\title{
(en)CANTO ESCONDIDO
}

Paulo Bernardino Bastos Estudos de Arte, PH.D. (ua.pt); Escultura [M.A. (rca. uk), LIC. (esbap.pt)]. Investigador em artes visuais/plásticas. $\mathrm{O}$ seu trabalho interliga vários materiais/disciplinas. Através de metáforas conecta fronteiras físicas e emocionais construindo espaços com significados múltiplos. Participa em vários eventos internacionais e nacionais como artista e conferencista. Universidade de Aveiro / Universidade do Porto | Portugal Praxis and Poiesis: from arts practice towards art theory http://www.idmais.org/about/structure/praxis-and-poiesis/ ID+ Instituto de Investigação em Design, Media e Cultura. <pbernard@ua.pt > ORCID: 0000-0001-8883-9967
Resumo Este artigo resulta da reflexão sobre a construção da obra "(en)CANTO ESCONDIDO", uma escultura/instalação que intervém in situ captando as relações dinâmicas entre materiais, paisagem e habitats de Coruche, em Portugal. 0 projeto apela às relações permeáveis entre natureza e cultura. o fluxo de presença/ausência dos animais que visitaram a escultura eram parte integrante da lógica da instalação. A obra pretendeu potenciar relações de observação dinâmicas em que o observador se tornava observado, constatando a sua evidente parte na natureza. "(en)CANTO ESCONDIDO" é simultaneamente um modelo de observatório urbano das migrações (insetos e pássaros) e uma construção arquitetural que invoca relações de convivência e partilha interespécie/intergeracional que incitam a interação e a descoberta de novas relações. A instalação pretendeu levar os observadores a um espaço de imersão, onde a realidade da natureza circundante se funde nas memórias e ficções de cada visitante. Foi uma experiência de partilha e um exercício estético e de reflexão sobre a sustentabilidade na nossa prática que se tornou uma experiência comunitária de partilha com imenso potencial narrativo e reflexivo.

Palavras chave Instalação, Observatório, Migrações, Arte pública, Natureza/Cultura. 
Maria Manuela Lopes é artista plástica com prática transdisciplinar, investigando relações de memória e identidade. Escultora -FBAUP, MA -Goldsmiths College. PhD-Brighton e PostDoc- ID+ UA e i3S Porto onde é investigadora corresponsável pela Interface Cultural Arte/Ciência. É docente do Ensino Superior Artístico, faz curadoria e a sua obra é mostrada a nível nacional e internacional. É co-fundadora e diretora adjunta dos programas de residência artística: Ectopia e Cultivamos Cultura. IBMC Instituto Biologia Molecular e Celular (i3S Instituto de Inovação e Investigação em Saúde)| Universidade do Porto, Portugal <maria.lopes@i3s.up.pt > ORCID: 0000-0003-1207-3525

\section{(en)CANTO ESCONDIDO}

Abstract This paper results from the reflection on the construction of the artwork "(en)CANTO ESCONDIDO", a sculpture / installation that intervenes in situ capturing the dynamic relationships between materials, landscape and habitats of Coruche, in Portugal. The project calls for intertwined relations between nature and culture. The flow of presence / absence of animals that visited the sculpture was an integral part of the installation's logic. The work intended to enhance dynamic observation relationships in which the observer became observed, noting its evident part in nature. "(en)CANTO ESCONDIDO"is simultaneously a model of urban observatory of migrations (insects and birds) and an architectural construction that invokes dialogical connections of coexistence and inter-species / inter-generational sharing that incite interaction and the discovery of new relationships. The installation intended to take observers to an immersion space, where the reality of the surrounding nature merges into the memories and fictions of each visitor. It was an experience of sharing and an aesthetic exercise and a reflection on sustainability in our practice, that became a community experience of sharing with immense narrative and reflective potential.

Keywords Installation, Observatory, Migration, Public art, Nature / Culture.

\section{(en)CANTO ESCONDIDO}

Resumen Este artículo es el resultado de la reflexión sobre la construcción de la obra "(en) CANTO ESCONDIDO", una escultura / instalación que interviene in situ capturando las relaciones dinámicas entre materiales, paisajes y hábitats de Coruche, en Portugal. El proyecto demanda relaciones permeables entre la naturaleza y la cultura. El flujo de presencia / ausencia de animales que visitaron la escultura fue una parte integral de la lógica de la instalación. El trabajo pretendía mejorar las relaciones de observación dinámicas en las que el observador se observaba, señalando su parte evidente en la naturaleza. "(EN) ESCONDIDO CANTO" es a la vez un modelo de observatorio urbano de migraciones (insectos y aves) y una construcción arquitectónica que invoca conexiones dialógicas de convivencia e intercambio entre especies / entre generaciones, que incitan a la interacción y al descubrimiento de nuevas relaciones. La instalación pretendía llevar a los observadores a un espacio de inmersión, donde la realidad de la naturaleza circundante se funde con los recuerdos y las ficciones de cada visitante. Fue una experiencia de compartir y un ejercicio estético y una reflexión sobre la sostenibilidad en nuestra práctica, que se convirtió en una experiencia comunitaria de compartir con un inmenso potencial narrativo y reflexivo.

Palabras clave Instalación, Observatorio, Migración, Arte público, Naturaleza / Cultura. 


\section{Introdução}

O projeto “(en)CANTO ESCONDIDO" foi desenvolvido como proposta de participação de Paulo Bernardino Bastos e Maria Manuela Lopes na residência artística e festival "Percursos com Arte" em Coruche durante o ano de 2019 entre julho e outubro. Coruche, é uma vila portuguesa pertencente ao Distrito de Santarém, no Ribatejo, em Portugal, com cerca de 9000 habitantes.

Esta obra veio no contínuo de trabalhos que temos desenvolvido em parceria (Lopes e Bastos 2016) e no conveniente que se tornou esta oportunidade de participar na Bienal e nas residências que ela contemplava, encarando esta possibilidade de trabalhar no local, como um bom momento para explorar o nosso entendimento das questões de sustentabilidade e de fluxo em relação à nossa prática artística. A residência começou a 1 de julho e durou três semanas. Em agosto e parte de setembro trabalhamos no nosso atelier no Porto terminando alguns elementos que necessitavam de mais atenção. Depois voltamos a Coruche a meio de setembro para iniciar a montagem. $O$ festival inaugurou a 28 de setembro ficando com programação até dia 13 de outubro.

O nosso projeto não contemplava um desenho prévio, a não ser um muito esquemático de alguns objetos que se poderiam entender como 'casas' para pássaros e o desejo de interagir com árvores locais. Queríamos aproveitar o local, um local novo para nós, e desenvolver algo que fosse para Coruche, mais especificamente para o bairro onde esse ano se centraria a Bienal, mas também que fosse sobre Coruche, e com Coruche. De forma aberta fomos procurando dar forma à obra com os materiais, sensações e sentimentos que construíamos em cada dia na região. Coruche é no Ribatejo, mas o território passa pelo Alentejo e volta ao Ribatejo (só mesmo consultando um mapa ou navegando o território presencialmente se percebe essa relação), ou seja, o mapa é fruto de uma herança de um passado em que as famílias influentes e os seus domínios e convicções definiam as fronteiras regionais. 0 terreno típico da região é o montado, que se traduz num ecossistema particular de influência humana com florestas de sobreiros e azinheiras, carvalhos e castanheiros. São zonas com um ecossistema muito rico com imensas espécies distintas e em que cortiça é a principal riqueza extraída. 0 montado é protegido legalmente e típico do mediterrâneo (Portugal e Espanha, Argélia e Marrocos). Coruche é quente, com casas caiadas de branco com risca colorida a contornar as janelas, tem touros e tourada, termos próprios e histórias peculiares.

De repente, sem aviso prévio, entramos para um mundo que parecia um outro país, uma cultura que seria próxima e partilhava vários valores comuns, mas que trazia imensa novidade. Um novo léxico se fez familiar e novos termos (que por conhecidos que fossem estavam longe de percorrer as nossas discussões do que e como fazer algo) entraram no quotidiano; termos como lezíria, charneca, montado, cortiça, barro, carvão, rio, touro, tourada, anta, bolota, passaram a ser comuns e a permear as nossas conversas. 
À chegada visitamos o montado, o museu municipal, algumas igrejas em lugares fora do centro da vila, uma fábrica de carvão, alguns locais históricos implicados na história recente de Portugal e alguns monumentos funerários da pré-história. Foi para nós uma descoberta. Os dias longos de Verão eram mesmo muito quentes e secos, o rio não tinha condições de acolher banhos e o que nos trazia eram mosquitos ao entardecer, a comida era um desafio diário, pois ali comem essencialmente carne, bolotas e até touro (que claro também é carne e se chama novilho bravo no menu dos restaurantes, mas é uma carne rara no resto do país). 0 som dos pássaros era superintenso e permeava a rua de manhã cedo e ao entardecer com uma música nova para os nossos ouvidos citadinos.

\section{Local - atelier e instalação e a questão do jardim}

Ficamos instalados numa casa em comum com os outros 5 artistas e trabalhávamos na antiga Adega do Joaquim Eugénio da Silva, gentilmente cedida pela neta Clara Joaquim. Esta adega era fresca e no 'bairro novo das Artes' (antigamente apelidado de bairro das ex-colónias portuguesas com nomes de países do antigo império). 0 local escolhido por nós para acolher o projeto foi o jardim localizado no início do bairro. Era um local calmo, com diversidade de fauna e flora e com arranjo ajardinado. Ficava entre a esquadra de polícia (GNR) e a escola primária, tinha bastante circulação de pessoas e bastante variedade de pássaros ao entardecer.

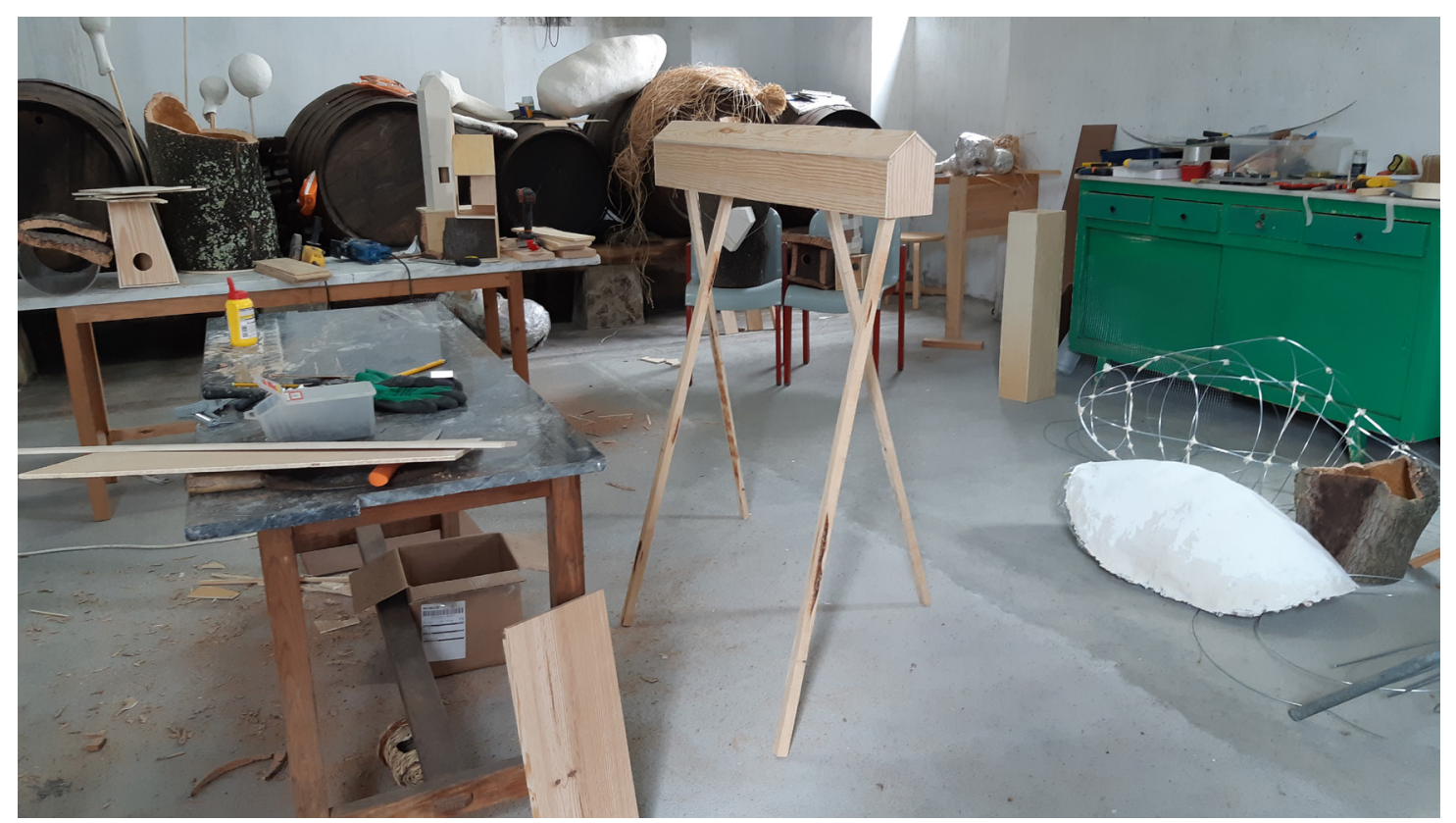

Fig 1. Atelier

Fonte: os autores 
A escolha do jardim como local de acolhimento não foi desinteressada por nossa parte. A discussão da política global de jardins está localizada no ponto de mudança de paradigma estético dos estudos internacionais como menciona Shapiro (2013) que sustenta que muitas questões de diplomacia, guerra e paz podem ser exploradas com lucro através de uma montagem de dinâmica conceitual: utopia / distopia / heterotopia, (re)distribuição sensível, governança / resistência cultural e civil / militar. Segundo Shapiro (2013) é frequente entender os jardins como um espaço utópico: um lugar tranquilo, uma ilha feliz de serenidade apolítica, onde as pessoas se envolvem em contemplação, brincadeira e prazer sensorial. Não tivemos ilusões um jardim é mais complexo, particularmente aquele que pelo seu desenho 'estado novo' encerra um potencial político de resistência naquele local e que pela localização contempla uma frequência muito variada conforme a hora do dia. Segundo Diogo et al (2019) um jardim não deixa de ser uma paisagem projetada de mediação entre natureza e cultura, incorporando diferentes níveis de controle humano sobre o deserto, definindo regras específicas para esse confronto e encenando diferentes formas de domínio humano. Com todas estas referências era o local ideal para o lado dialógico que queríamos impor à obra.

\section{Sobre a Obra}

Realizada com madeira, cortiça, gesso, água, sementes, rafia, corda e outros materiais que se tornam estruturais, a escultura apresenta elementos que constituem, ao mesmo tempo, inscrição na paisagem de formas construídas e acolhimento para pássaros, insetos, borboletas etc. Sendo uma obra de exterior apresenta desafios específicos e uma forma de experiência particular. A instalação é simultaneamente um modelo de observatório urbano das migrações das várias espécies de insetos e pássaros e uma construção quase arquitetural do espaço envolvente. De certa forma pretende ser dependente das relações de partilha do espaço natureza/cultura que caraterizam o ambiente urbano/rural da zona de Coruche. Como um desenho tridimensional das perspectivas da paisagem local com as suas relações interligadas entre rio, sobrado, vila, árvore, cortiça, lezíria, ruralidade, lusofonia etc., a obra reflete a vontade de intervir in situ captando as relações dinâmicas entre os materiais e paisagens locais, os habitats das pessoas e animais locais e os visitantes esporádicos.

(en)CANTO ESCONDIDO vem na sequência de outras obras que temos desenvolvido em que refletimos sobre a relação natureza/cultura e a caraterística dos Humanos como espécie com autoconsciência e capacidade questionar a sua existência/consciência. Nesta instalação apelamos às relações de fronteira entre natureza e cultura numa polarização em que chamamos elementos naturais (vivos e inertes) a fazerem parte da instalação. O fluxo de presença/ausência dos animais que visitaram a escultura foram parte integrante da dinâmica da instalação, assim como a intervenção hu- 
mana que tendencialmente ajudou a potenciar a relação de visita, incrementando os elementos que os vários insetos e pássaros possam gostar. A obra potência relações de observação dinâmicas em que observador se torna observado - em que as várias espécies tomam consciência da presença e movimento das outras para visitar a instalação. Além da mutação frequente destas visitas e dos ciclos de alimento/acolhimento que se poderiam criar, a própria mudança de estação e de tempo poderia cambiar a frequência da obra e a sua percepção no espaço influenciando as vivências da obra e da própria vila.

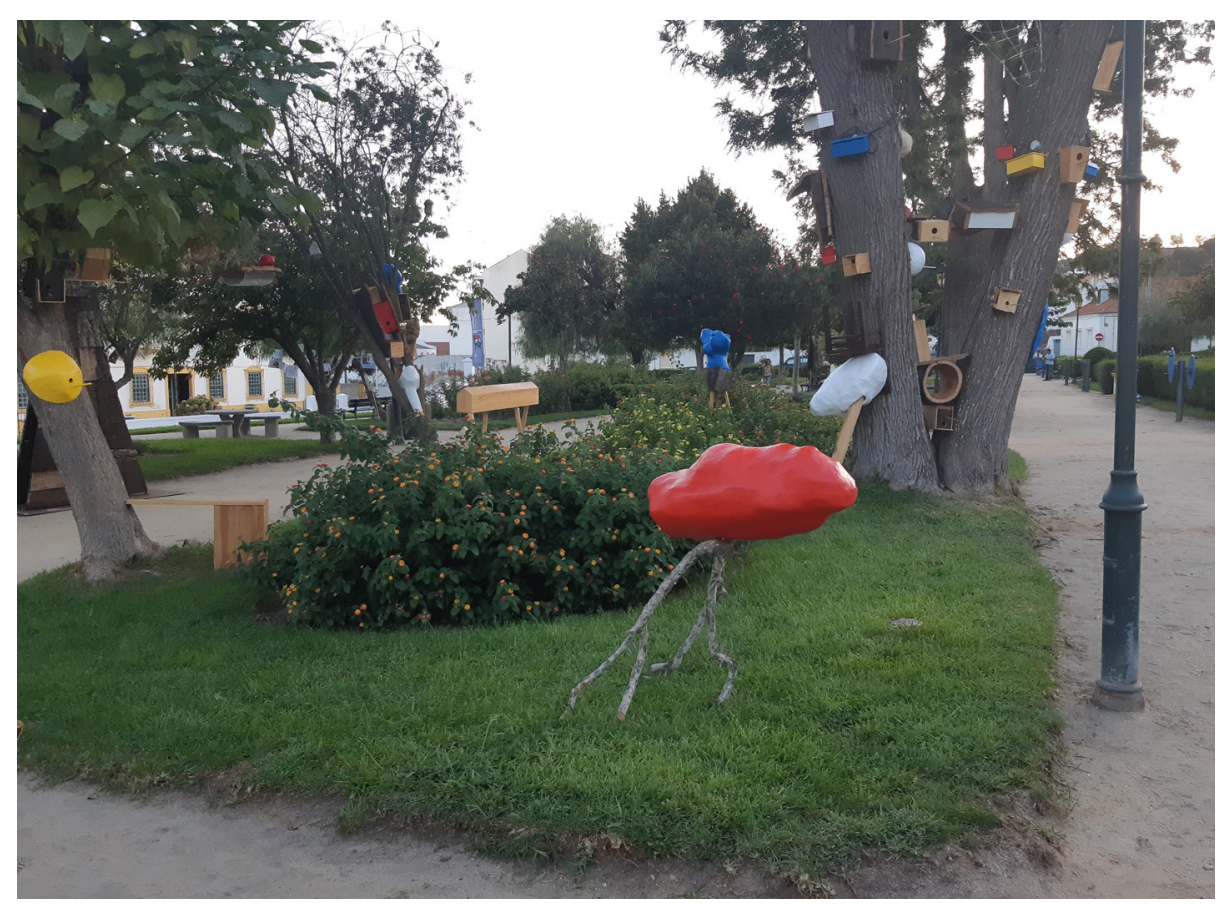

Se por um lado a visita a exposições pode trazer ao público assunto e ser recompensador em termos de experiência emocional, a observação de pássaros é procurada pela simplicidade da iniciação e pela sensação de calma e de tempo que proporciona. (en)CANTO ESCONDIDO apela à convivência entre as pessoas e à partilha intergeracional que distribuindo o conhecimento podem alimentar a interação da instalação e a descoberta de novas relações de convivência. Neste caso pensamos que os mais experientes poderiam ajudar os mais novos a descobrir formas de atrair mais espécies de pássaros e insetos e explicar-lhes algo sobre as migrações e a cadeia de alimentação dos animais.

A instalação integrou som (contendo canto de pássaros locais) e 'casas' para pássaros como espaços encantados, alegorias à mente, onde valores convencionais que nos são impostos pela consciência são questionados. 
A instalação pretendeu levar os observadores a um espaço de imersão (encanto), onde a realidade da natureza circundante se fundia nas memórias e ficções de cada visitante interligando as versões locais e as ligações aos materiais e lugar, com as impressões dos visitantes ocasionais que vão se apropriavam da paisagem já com a instalação nela.

A ideia foi a de construir a instalação de forma integrada na paisagem urbana, preferencialmente a partir de uma ou duas árvores (como resultou e podem observar nas imagens).

\section{Residência e processo de construção}

Entre 1 e 19 de julho estivemos em residência, todos os dias estivemos na rua a recolher sons locais, a ver os materiais que constituíam a vila, a falar com a população do lugar, sobrevivemos aos $45^{\circ}$ centígrados e aos mosquitos, passando por touradas e corte de cortiça, por exploração de materiais locais como a madeira, o gesso, o barro, o calor das fábricas de carvão, o papel e a cortiça e explorando as dinâmicas de heterogeneidade que encontramos tanto nas características do bairro das artes como nos azulejos das igrejas que visitamos. Esse período permitiu o desenvolvimento do projeto. Pretendíamos com a saída do ambiente habitual em que trabalhamos criar associações novas em presença do espaço, costumes, tempo e materiais novos. Neste espaço construímos módulos do (en)CANTO ESCONDIDO e planeamos até certo ponto a sua assemblagem na instalação final. Este tempo serviu para as recolhas de sons de ambiente de pássaros locais em diversos pontos da paisagem envolvente, ampliando a abrangência da obra na sua colocação espacial final. Cada dia construíamos algum módulo em cortiça ou madeira e dávamos andamento a outras formas orgânicas inspiradas nos desenhos que recolhíamos das visitas ao montado ou de andar na rua. As formas orgânicas foram construídas de papel ou em pasta de papel e por isso eram demoradas na sua execução camada a camada de meia peça de cada vez. A lentidão do processo permitia as visitas constantes dos transeuntes ao atelier/adega que passavam e cumprimentavam e ao fim de uns dias, talvez de verem as obras cá fora a secar, já entravam e perguntavam o que estávamos a fazer (e claro aproveitavam para descansar do sol e calor da rua). Desta forma descomprometida fomos ensinando a crianças algumas técnicas e descobrindo o que a comunidade entendia ou gostava dos nossos módulos. Fomos também aprendendo sobre formas de cortar cortiça e sobre os vários usos que lhe dão naquele lugar. Fomos partilhando a generosidade da partilha de todos a quem pedimos a cedência deste ou daquele bocado de madeira ou ramo ou cortiça ou ferramenta. Foi uma experiência imersiva todo o tempo. 


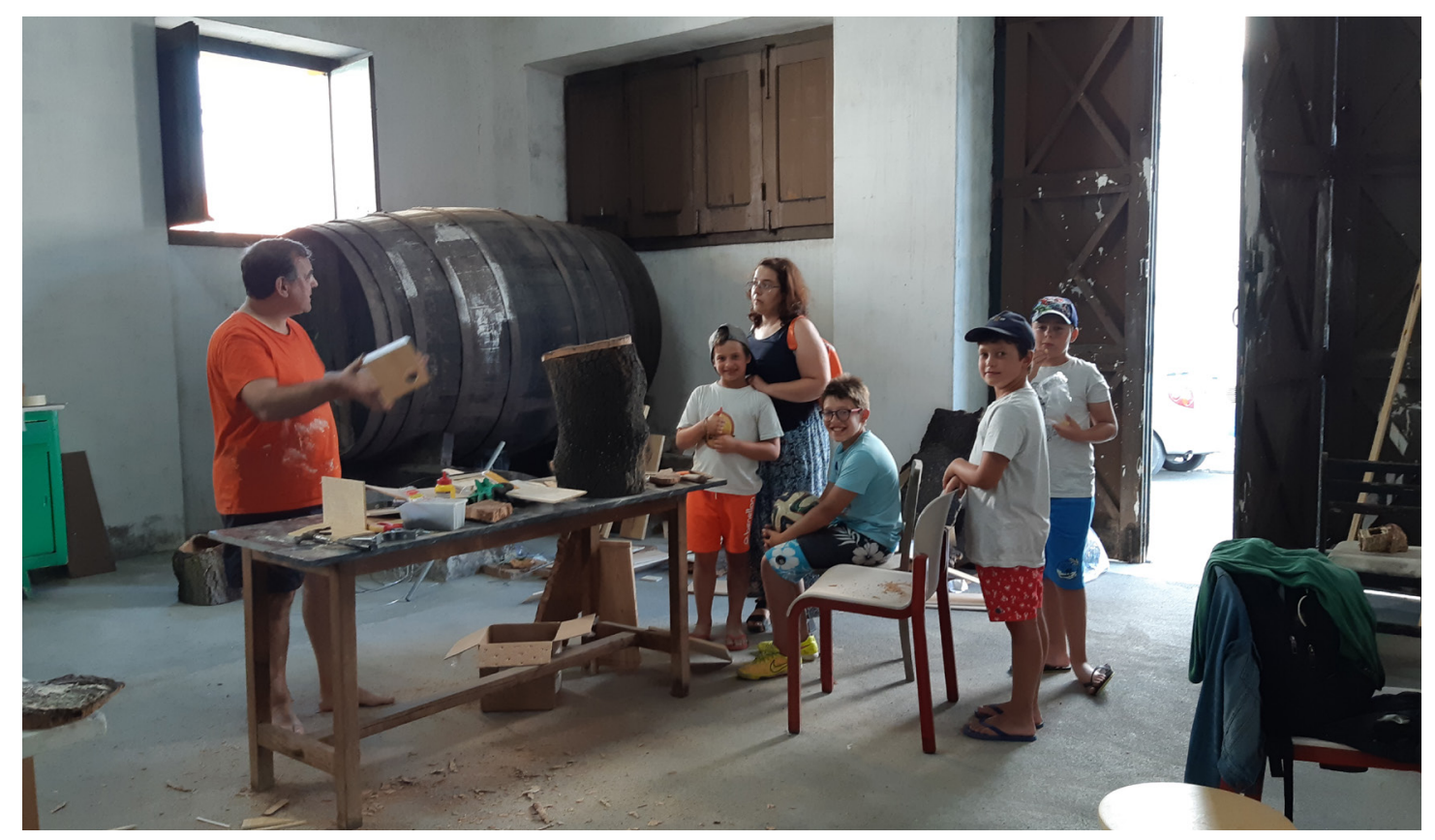

Fig 5. Atelier

Fonte: os autores

\section{Reflexão}

Este artigo considera a questão da sustentabilidade e estética da perscpetiva da reflexão crítica dos dois artistas sobre a sua prática artística ligada ao ambiente ou sobre a sustentabilidade da sua arte. Adota uma abordagem de auto narrativa, examinando a maneira como conceitos de diferentes disciplinas e as suas práticas quando em conjunto numa prática de coletivo juntamente com alusões às "três ecologias" de Guattari (2000). Guattari argumenta que a arte e a estética têm um papel na sustentabilidade "não solidificada" e que a arte como modo de ser coletivo possibilita numa nova maneira do homem pensar a relação com a sua subjetividade, com a sociedade e com o meio ambiente. Por esse lado esta reflexão contém um exemplo baseado na prática e apela a uma estética da ação diante das incertezas inevitáveis inerentes a uma cosmovisão ecológica.

Cremos que, como as três ecologias de Guattari (2000) (en)CANTO ESCONDIDO apela ao pensar, numa tentativa de devolver à humanidade sua condição de ser integrado no mundo, e não fragmentado e isolado como hoje vivenciamos no estilo de vida capitalista e apresentado nas teorias pós-modernistas. Se a obra de Guattari nos estimula a questionar todas as esferas sociais, segundo o próprio, a reinventar maneiras de ser no seio do casal, da família, do contexto urbano, do trabalho, etc. a nossa obra pretende falar de sustentabilidade de uma forma pratica e concreta e não vazia em comentário onde os produtos/ações podem ser rotulados como 'sustentáveis' sem discernir a questão de grau ou qualidade. 
Fig 7. (en)CANTO ESCONDIDO Fonte: os autores

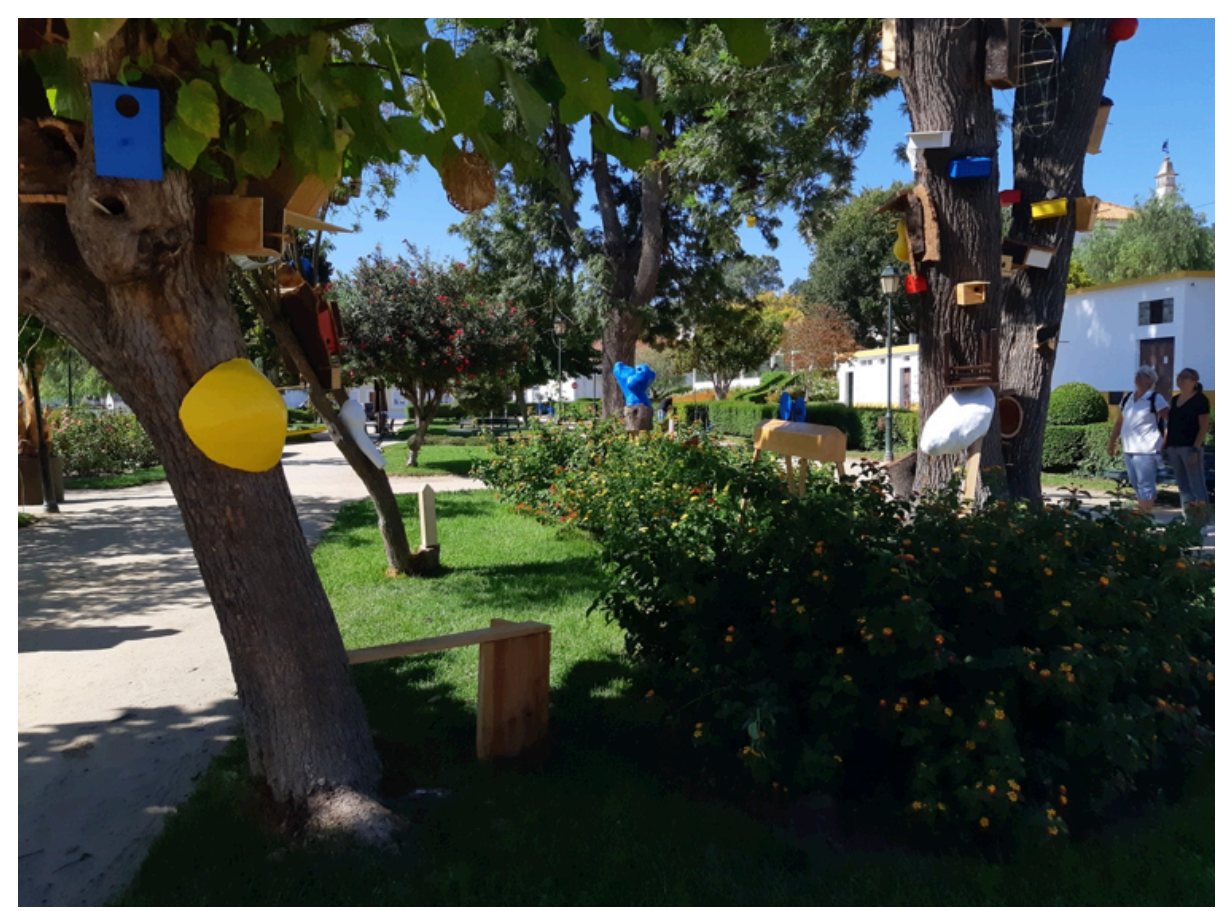

A sustentabilidade acontece lentamente e cresce e pode ser tornada predominante no governo e nas empresas quanto mais suscetível a pequenos ajustes de produtos ou sistemas, em vez de mudanças abruptas. Ao nível do indivíduo, cada racionalização de pequenas mudanças em nossas vidas (que num local de interior que vive muito mais de perto essa relação de ecossistema - o sobrado e os habitantes vivem em interdependência cuidando-se mutuamente) parecem nulas, mas não nos podemos iludir sobre o impacto que estamos tendo. Todos os dias somos confrontados com as notícias de que não estamos abordando adequadamente a natureza e à escala dos problemas que estamos enfrentando. A percepção de que estamos vivendo no Antropoceno exige mais que reconsideremos nossa posição centrada no ser humano. Se o desaparecimento do ambientalismo já foi proclamado em 2006 por Shellenberger \& Nordhaus, em 2012 Mentz já afirmava que estamos num mundo pós-sustentável. Parte do enquadramento crítico de uma estética da sustentabilidade já foi explorada por artistas e pensadores desde os pioneiros Helen Mayer Harrison e Newton Harrison (1985) sendo que a natureza ampla da sustentabilidade reflete a complexidade do ambientalismo e permite muitas abordagens estéticas diferentes. (en)CANTO ESCONDIDO apresenta algumas características que o podem enquadram como um projeto artístico ambiental na sua responsabilidade perante o ambiente e respeito no uso dos materiais não tóxicos na inter-relação que estabelece com a comunidade local de natureza (flora, fauna e humanos),na forma como propicia conexões interespécies, valoriza o ambiente e chama a 
atenção para o mesmo, incorporou um método experimental e um processo iterativo e participativo na sua construção e ainda é adaptável de na forma como foi encarado efémero. Acreditamos ser possível criar sistemas adaptativos complexos, pensar e agir além das fronteiras. Uma estética pós-sustentável pede aos criadores / espectadores / participantes que diminuam seu consumo e também que façam uma perspectiva transdisciplinar em que diferentes níveis de realidade são geridos por diferentes tipos de lógica. (en)CANTO ESCONDIDO vive de uma relação permanente ente materiais orgânicos e seres vivos.

Nosso trabalho mantém um silêncio político e estético baseado em narrativas e observações pessoais, contendo estórias que nos contaram e cenas que fomos assistindo do banco do jardim ou da mesa do café, que incorporam os aspetos emocionais e psicológicos das consequências de atos quase violentos. A experiência é a de partilha e cooperação, mas também está presente a ideia de ausência, da violência contra a natureza, a violência da opressão, do imperialismo e das ditaduras, a violência dos conflitos étnicos ou de gênero silenciados, mas todas essas ideias são mostradas da maneira mais silenciosa possível envoltas em camadas sucessivas de agregados de vários módulos que pululam o jardim.

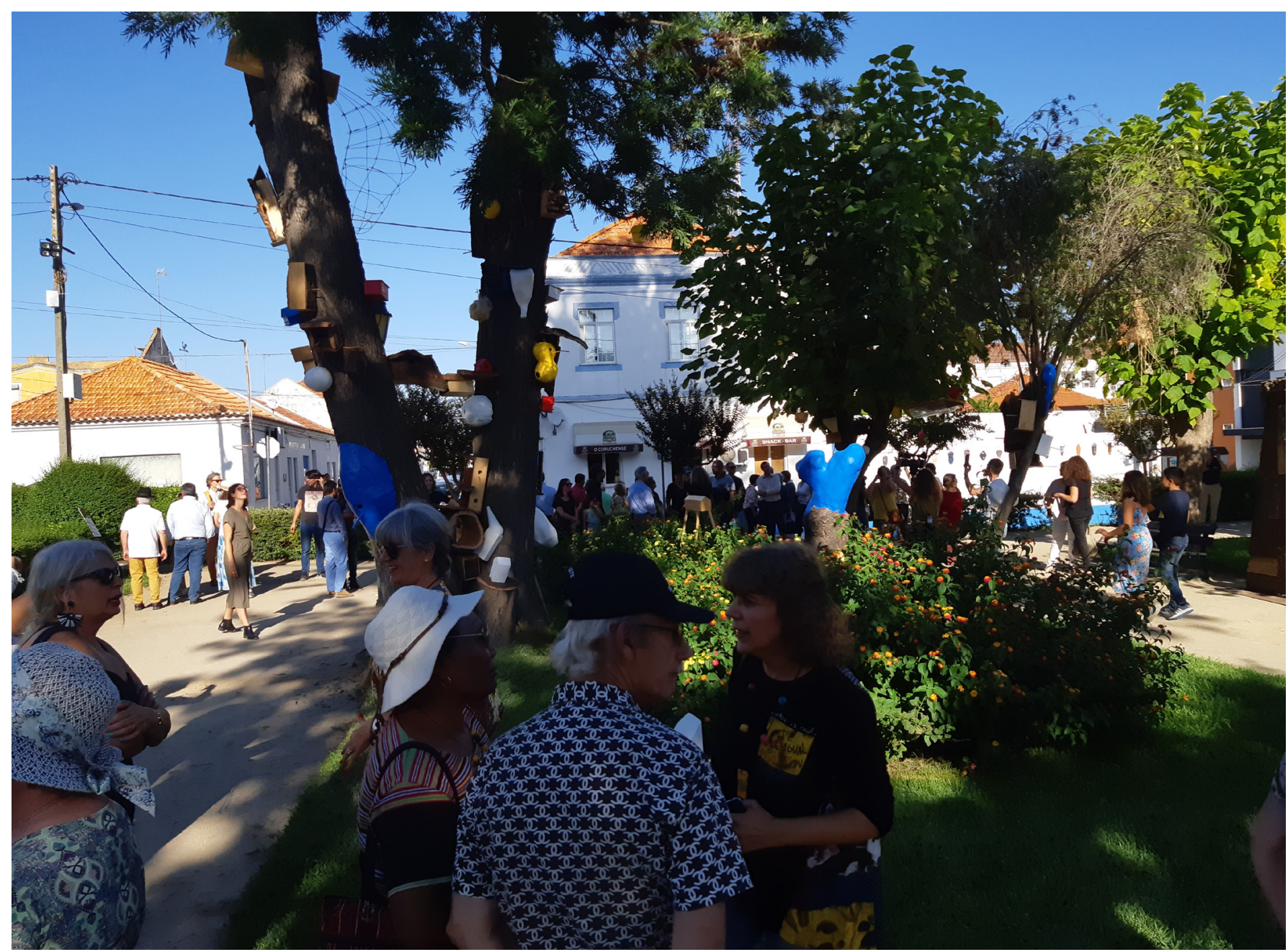




\section{Observações finais}

Através de um processo de coautoria para esta obra e artigo consideramos relacionamentos entre o ambiente físico e mediado representações e como isso se reflete criando um mapa cultural de um ambiente e de ligar narrativas distintas. $O$ trabalho também destaca a importância da experiência, de coconstrução e de sustentabilidade, o conceito de transdisciplinar em artes e ciências, e possibilidades de transformação e fluxo. A narrativa da construção e existência do projeto inclui elementos sociais, políticos e biográficos também vivências dos materiais e do processo de criação e coconstrução da instalação. A história que com esta reflexão partilhamos fornece informações que orientam o espectador a ver o trabalho através de uma lente específica, posicionando-o na distância certa para trazer uma conexão emocional e uma apreciação e compreensão mais profundas. Estabelece uma conexão entre a instalação e o que ele pode significar: uma ressonância que provoca uma transformação dos objetos e ajuda a transcender sua imanência.

A experiência de construção na comunidade e para um jardim/parque público permitiu o desenvolvimento de um sentido de comunidade que estranhamente nos envolvia enquanto não pertencentes, mas autorizados por uma espécie de livre trânsito. 0 espaço do jardim, pela presença da nossa obra e de todo o festival sentiu uma revitalização temporária que permitiu o crescimento do orgulho da comunidade em pertencer àquele bairro $\mathrm{e}$ em fazer daquele jardim o jardim deles. A forma de lenta construção da obra (na primeira parte da residência no espaço da adega e na segunda parte no jardim e nos translados entre um local e outro) permitiram que os locais e transeuntes fosse participando na construção da obra dando-lhes uma sensação de quase pertença e de carinho quando finalmente foi inaugurada. A instalação foi mantida e cuidada pelos Coruchenses e visitantes durante as 3 semanas de exibição do festival e transeuntes pararam para ajudar a desmontar do mesmo modo que o fizeram quando estávamos a colocar os mais de sessenta elementos nas árvores e espaço ajardinado. Participaram até ao fim e nos pediram desculpa por não conseguirem que a obra permanecesse para sempre lá. Para nós e para os pássaros que já circulavam pelos espaços da obra, provavelmente com a mesma ligeireza que as crianças que brincam no jardim ou parque de diversões a obra foi extremamente bem-sucedida em envolver a comunidade. Em grande parte das vezes o sentido de pertença ou de identificação não é tão bem conseguido como neste caso (mesmo em outras obras públicas que já construímos ou apresentamos) pois a arte encerra geralmente um nível de especificidade que afasta os não versados na cultura contemporânea que se desviam dizendo que não percebem e que nos acusam de elitismo. $O$ que concluímos ter sido conseguido foi ter a arte como verdadeiro catalisador de comunicação intergeracional e intersocial com vários habitantes locais ou regionais a virem explicar publicamente informações sobre pássaros e ou animais locais que gostariam de 'casa' como 
as que a nossa obra lhes estava a proporcionar ou mesmo sobre a possibilidade de criação de um novo ecossistema em que a comida iria chamar rastejantes, que iriam atrair outros animais para os comer ou pássaros e outros pássaros maiores. No final até herdamos elementos 'casas', pois voluntários levaram para junto do nosso 'condomínio' como carinhosamente lhe chamavam oferendas de casas de pássaros que tinham construído ou que pássaros tinham deixado para trás. Ou seja, a obra foi cuidada, viveu e até cresceu. Aprendemos com a experiência a ser mais humildes e que a empatia e generosidade com a arte se podem encontrar em todos os lados mesmo nos que aparentemente não esperávamos.

\section{Referências}

Diogo M. P., Simões A., Rodrigues A.D., Scarso D. (2019) Gardens and Human Agency in the Anthropocene, Routledge Environmental Humanities

Guattari, F. (2000). The three ecologies (I. Pindar \& P. Sutton, Trans.). London: Athlone Press. Lopes, M. Manuela \& Bastos, P.B. (2016) "Participação Colaborativa: Reflexões Sobre Práticas Enquanto Artistas Visuais", in Mutações, confluências e experimentações na Arte e Tecnologia. Venturelli, S. \& Rocha C. (ed), 2016, PPGARTE/ UNB, pp. 147-168. ISBN: 978 - 85 - 89698-50-4.

Mentz,S.(2012).After sustainability.PMLA,127(3),586-592.doi:10.1632/pmla.2012.127.3.586. Shapiro, Michael J. (2013). Studies in Trans-Disciplinary Method: After the Aesthetic Turn. New York: Routledge.

Shellenberger, M., \& Nordhaus, T. (2006). Post-environmentalism. In M. Andrews (Ed.), Land, Art: A Cultural Ecology Handbook (pp. 196-199). London: Royal Society for the Arts. 